\title{
Analysis of human aldehyde dehydrogenases $(A L D H)$ gene expression pattern in breast cancer tissue samples: rutin-copper complex inhibit the breast cancer cell proliferation
}

Shridhar V. Pattar ${ }^{1}$, Manisha R. Mirjankarr', Suyamindra Kulkarni ${ }^{2}$, Pramod B. Gai', Namadev K. Pujar', H. G. Premakshi ${ }^{3}$, Sikandar I. Mulla ${ }^{4}$, R. L. Babu ${ }^{5}$ and Chandrappa M. Kamanavalli ${ }^{*}$

\begin{abstract}
Background: Higher aldehyde dehydrogenases $(A L D H)$ activity is one of the important signatures of breast cancer appearance and has been associated with poor prognosis. ALDH1A3 has been over-expressed in breast cancer patients. This study aims to analyze gene expression patterns of $18 \mathrm{ALDH}$ isozymes in breast cancer tissue samples. It is carried out using a chip-based microarray, next-generation DNA sequencing of ALDH2 gene following in silico study to identify the natural products which act as inhibitors for over-expressed $A L D H$ isoforms. The synthesis of rutin-copper complex and cell viability assay is carried out on MDA-MB-468 cell line.

Results: ALDH1A3 and ALDH18A1 have shown the highest positive mean fold of variation; whereas, ALDH2 and ALDH1A2 have shown the highest negative mean fold variation. In silico studies revealed that rutin has the highest binding affinity with both $A L D H 1 A 3$ and $A L D H 18 A 1$ and supported with $\mathrm{IC}_{50}$ value of rutin against MDA-MB-468 cells $(144.50 \mu \mathrm{g} / \mathrm{ml})$. Chemically synthesized rutin-copper complex significantly lowered the $I C_{50}$ value to $119.40 \mu \mathrm{g} / \mathrm{ml}$. The next-generation sequencing study provides the novel single nucleotide polymorphism (SNP) from T to $G$ in the ALDH2 gene.

Conclusion: The present study signifies that, along with ALDH1A3, ALDH18A1 also acts as a marker for breast cancer. Apart from that, inhibitors of ALDH1A3 and ALDH18A1 were attained. Perhaps the single nucleotide polymorphism (SNP) obtained during the mutation analysis may be the probable cause of the highest downregulation of $A L D H 2$ in breast cancer.
\end{abstract}

Keywords: Aldehyde dehydrogenases, Breast cancer, Molecular docking, Rutin

\footnotetext{
* Correspondence: cmkamanavalli@gmail.com

'Department of Studies in Biochemistry, Karnatak University, Dharwad

580003 , India

Full list of author information is available at the end of the article
}

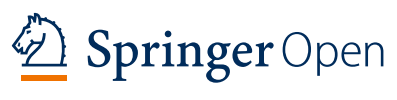

(c) The Author(s). 2021 Open Access This article is licensed under a Creative Commons Attribution 4.0 International License, which permits use, sharing, adaptation, distribution and reproduction in any medium or format, as long as you give appropriate credit to the original author(s) and the source, provide a link to the Creative Commons licence, and indicate if changes were made. The images or other third party material in this article are included in the article's Creative Commons licence, unless indicated otherwise in a credit line to the material. If material is not included in the article's Creative Commons licence and your intended use is not permitted by statutory regulation or exceeds the permitted use, you will need to obtain permission directly from the copyright holder. To view a copy of this licence, visit http://creativecommons.org/licenses/by/4.0/. 


\section{Background}

Breast cancer (BC) is the second most common cancer that leads to the death of women globally [1]. In India and other Asian countries, the incidence of breast cancer continue to be on the rise and every year nearly half a lakh women lose their lives due to this deadly cancer [2]. The BC tumors, which were not expressing estrogen (ER), human epidermal growth factor receptor (HER2) and progesterone receptor (PR) denote as triple-negative breast cancer (TNBC) [3]. A variety of factors associated with breast cancer like age, family history, lifestyle, hormonal regulation, alcohol consumption, and smoking are chiefly responsible for this pathogenesis [4].

There are several biomarkers used for diagnosis of breast cancer [5]. Over-expressed genes in early stages of breast cancer, such as tumor protein 53 (TP53), phosphoinositide-3-kinase-catalytic-alpha polypeptide (PIK3CA), human epidermal growth factor receptor 2 (HER2) ERBB2, fibroblast growth factor receptor 1 (FGFR1), myelocytomatosis oncogene (MYC), and phosphatase and tensin homolog (PTEN) [6] given in (Table 1) are extensively studied. In humans, aldehyde dehydrogenases $(A L D H s)$ are mainly involved in aldehyde detoxification and are also important in the synthesis of retinoic acid [7]. They also play a vital role in alcohol metabolism by removing aldehydes [8]. Among 18 different isoforms of $A L D H$, the activity of each isoform differs from the other according to the localization and tissue distribution.

Several studies have reported that $A L D H$ is a specific cancer stem cell (CSC) marker in solid tumors like breast, colon, and lung. The isoforms ALDH1L1, ALDH1A1, ALDH1, ALDH1A3, ALDH2, ALDH1A2, ALDH3A1, and $A L D H 7 A 1$ have been associated with different types of tumors. Among these genes, ALDH1A3 which is predominantly expressed in kidney, salivary glands, stomach, and thus over-expressed in breast cancer [9]. Diverse chemotherapeutic treatments also interfere with increased activity of $A L D H$. Certain biomarkers that lead to breast cancer can be used for proper analysis and further treatment [10]. Recent data suggest that there is a high demand for naturally extracted bioactive compounds for their anticancer properties worldwide [11]. Few findings also suggest that some phytochemicals can stimulate apoptosis in malignant cells in both in vivo and in vitro [12].

The rutin (quercetin glycoside) has tremendous clinical applications which include anti-inflammatory, anti-oxidant, and inhibition of platelet aggregation [13]. Rutin acts as an adjuvant agent that increases the cytotoxic efficiency of two important chemotherapeutic drugs viz., cyclophosphamide (CYC) and methotrexate (MTX) in MDA-MB-231 breast cancer cells [14]. In our present study, we investigated the differential expression patterns of all isoforms of $A L D H$ genes in human breast cancer tissue samples and also synthesized the rutin-copper complex to understand the differences in the efficiency of anticancer potentials. In silico molecular modelling studies lead to new innovation in designing novel drugs as this study requires less time and can be performed with large quantities of ligands. Besides, it is easy to compare and is found effective in screening [15]. In this study, we have used 12 natural bioactive compounds (Table 2) against ALDH1A3 and ALDH18A1 proteins through computational in silico docking. Next-generation sequencing (NGS) was carried out for $A L D H 2$ gene using illumina platform.

\section{Methods}

\section{Selection of patient sample and materials used}

RNA isolation kit RNA easy Minikit (Cat-74104), Agilent's Quick-Amp labeling Kit (p/n 5190-0442), TruSeq DNA sample preparation kit (Illumina, \#FC-1211001), Agencourt AMPURE XP beads (Beckman Coulter, \#A63881), 7500 Bioanalyzer Chips High Sensitivity Bioanalyzer Chips (Agilent, \#5067-4626), Oligo aCGH hybridization kit (Agilent, \# 5188-5380), Microarray slide backings (Agilent, \# G2534-60005), Human Cot-1 DNA (Invitrogen, \#15279-011), Oligo aCGH Wash buffer 1 and 2 set (Agilent, \#5188-5226), and Nuclease free water (Ambion, \#AM9939),

Table 1 Overexpressed genes in early breast cancer

\begin{tabular}{lll}
\hline Abbreviations & Gene & Function \\
\hline TP53 & Tumor protein 53 & Tumor suppressor \\
PIK3CA & Phosphoinositide-3-kinase-catalytic-alpha polypeptide & $\begin{array}{l}\text { Regulates PI3K signalling. } \\
\text { PI3K signalling is important for cell proliferation, migration of cells }\end{array}$ \\
ERBB2 (HER2) & Human epidermal growth factor receptor 2 (HER2) & Play an important role in breast cancer progression \\
FGFR1 & Fibroblast growth factor receptor 1 & Cell differentiation, growth, proliferation, migration \\
MYC & Myelocytomatosis oncogene & Acts as protooncogene \\
PTEN & Phosphatase and tensin homolog & Control cell movement, adhesion of cells to surrounding tissues, \\
\end{tabular}


Table 2 Name of natural bioactive compounds and their structures

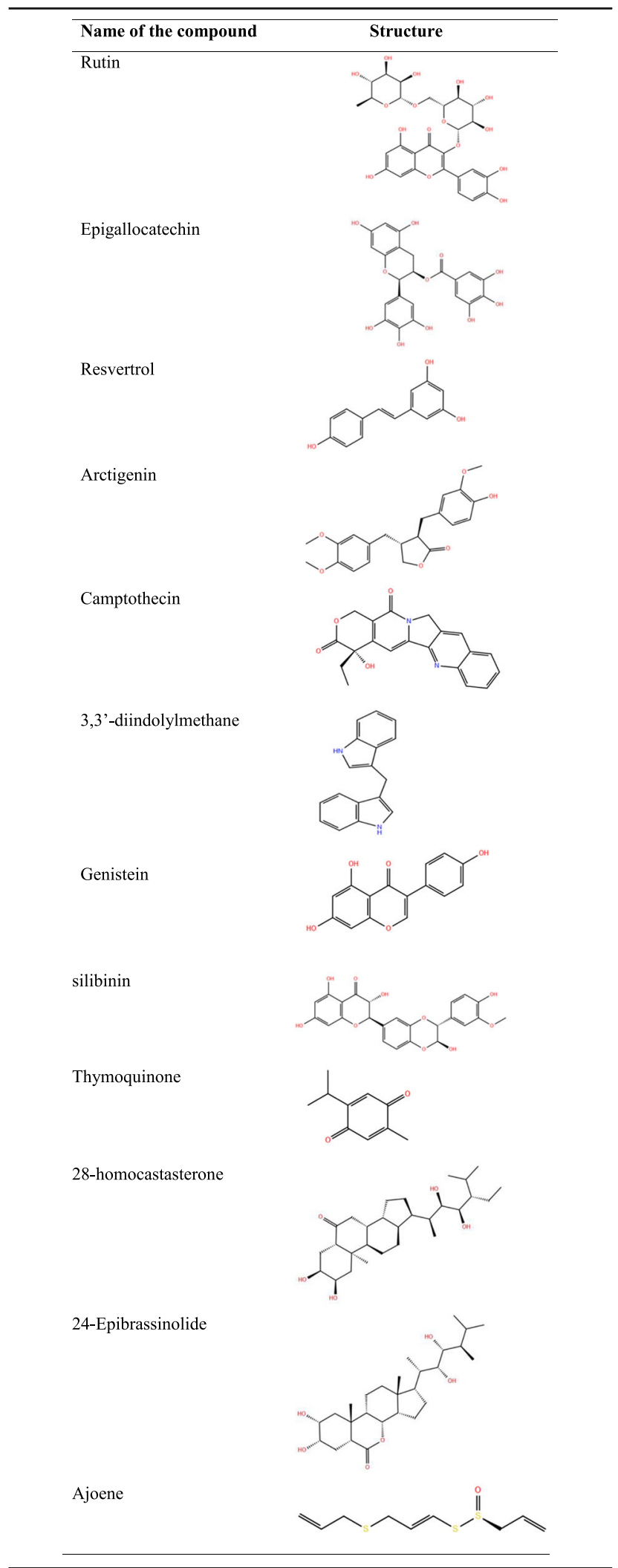

Bioruptor (Diagenode). Data of the breast cancer patients without any major clinical issues were included and nine tissue samples were collected from Dharwad, India. The tissue samples were stored at $-70{ }^{\circ} \mathrm{C}$ in RNAlater solution for further experimental use.

\section{Isolation of RNA and labeling the target}

RNA easy Minikit (Cat-74104) from Qiagen was used to isolate total RNA from tissue samples. RNA integrity analysis, cDNA synthesis, labeling, and microarray methods were carried out sequentially according to Kulkarni et al. [16].

\section{Next-generation DNA sequencing}

The next-generation DNA sequencing was performed at genotypic technologies private laboratory Bangalore. For this study nine breast cancer tissue samples were collected and used for sequencing of chromosome 12 of gene ID ENSG00000111275 using illumina sequencing platform. $100 \mathrm{bp}$ reads of illumina reads were sequenced using Illumina GAIIx Analyzer. The alignment software Burrows-Wheeler Aligner (BWA version 0.5.9 r16) was used to perform the gapped alignment of illumina sequences against the reference sequence. Alignment software bowtie (version 0.12.7) was used to perform ungapped alignment of illumina sequences against the reference sequence. Samtools (version samtools-0.1.7a) 2 was used for calling SNPs. The procedure flow chart is given in Fig. 1.

\section{Synthesis of rutin-copper complex}

The stoichiometric mixture of rutin and copper chloride dehydrate of $1 \mathrm{mmol}$ and $1.5 \mathrm{mmol}$ were used respectively in methanol solvent and reflux for $5 \mathrm{~h}$. The resulting pale yellow precipitate was dried and washed three times with a mixture of 1:3 (ethanol-water) and was dried. The resultant was used for further experimentation and analysis [17].

\section{Cell culture and treatments}

Breast cancer cells (MDA-MB-468) were cultured in Dulbecco's modified eagle medium (DMEM) which was supplemented with $10 \%$ heat-inactivated fetal bovine serum (FBS) and $1 \times$ anti-myocotic solution. In each well of 96 wells flat bottom plate $200 \mu$ l of the cell suspension containing approximately 10,000 cells were seeded and cultured in $\mathrm{CO}_{2}$ incubator at $37{ }^{\circ} \mathrm{C}$ in $95 \%$ humidity by supplying $5 \% \mathrm{CO}_{2}$. The $100-600$ $\mu \mathrm{g} / \mathrm{ml}$ concentration of rutin and rutin-copper complex samples was used in the treatment of cells. The $\mathrm{IC}_{50}$ value for both rutin and rutin-copper complex was calculated after $24 \mathrm{~h}$ of experimental incubation time using GraphPad prism version 5.1 [18]. 


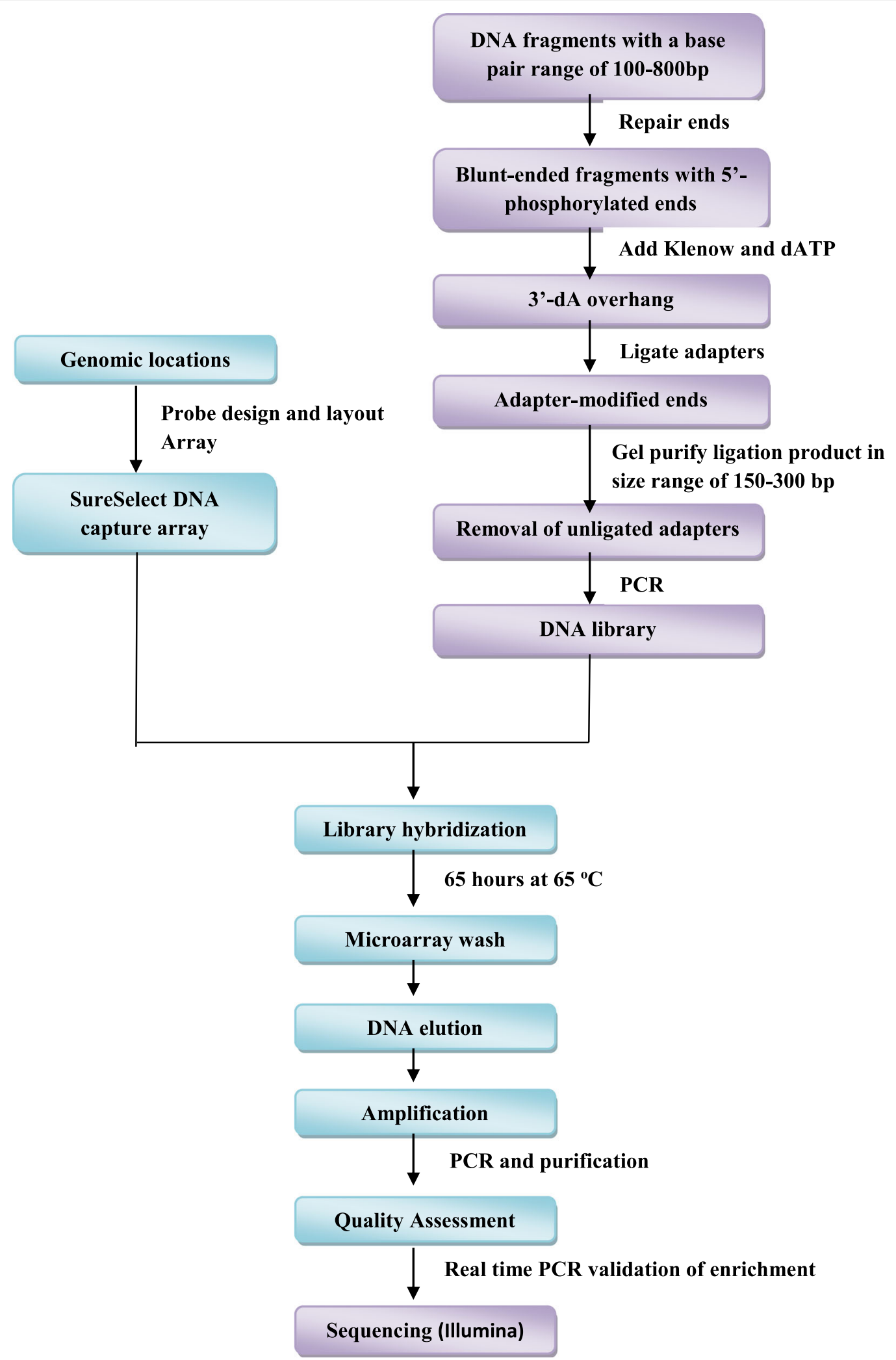

Fig. 1 Systematic workflow of NGS 
Table 3 Showing the list of fold variation in terms of gene expression profiling in ALDH isoforms

\begin{tabular}{ll}
\hline Gene name & Mean fold variation in breast cancer \\
\hline ALDH3B1 & -0.60 \\
ALDH4A1 & -2.0 \\
ALDH8A1 & -0.18 \\
ALDH6A1 & -2.22 \\
ALDH3A2 & -2.22 \\
ALDH5A1 & -1.26 \\
ALDH9A1 & -1.03 \\
ALDH16A1 & -0.31 \\
ALDH1B1 & -0.52 \\
ALDH1A2 & -3.12 \\
ALDH1L1 & -2.60 \\
ALDH18A1 & $\mathbf{1 . 9 3}$ \\
ALDH1A3 & $\mathbf{2 . 2 2}$ \\
ALDH3A1 & -1.03 \\
ALDH3B2 & 0.42 \\
ALDH2 & $-\mathbf{4 . 1 9}$ \\
ALDH7A1 & 0.24 \\
ALDH1A1 & -2.13 \\
\hline
\end{tabular}

Negative (-) sign indicates down regulation of the gene

\section{Molecular docking studies}

The molecular docking studies were performed on 12 natural compounds against $A L D H 1 A 3$ (5FHZ) and ALDH18A1 (Protein data bank PDBID-2H5G) using Schrödinger Maestro 11.2 version. The 3D structure of the protein ALDH1A3 (PDB ID-5FHZ) was retrieved from PDB. The protein was optimized accordingly, hydrogen was added and water components surrounding greater than $5 \AA$ were removed. Finally, it was minimized to the default root mean square deviation (RMSD) value of 0.30 using protein preparation wizard. Receptor grid generation was performed for minimized protein to identify the binding site of the ligand to the protein. The structures of natural compounds were drawn using 2D sketcher. They were performed using the Ligprep module to generate the $3 \mathrm{D}$ tautomer of the compound and to generate all combinations up to 32 per ligand. Ligand docking was performed according to the method of Kalirajan [19]. In Maestro 11.2 version dock, the binding of natural ligands to the active site of the human $A L D H 1 A 3$ is an automated process with extra precision (XP) descriptor information and added epik state penalties to docking score. The best bioactive conformation was finalized based on the highest $G$ score and highest number of interactions with the protein, mostly the number of hydrogen bonds. The XP visualizer was used as a tool to scrutinize the interactions. The scoring method was the most accepted design, with different parameters like polar, salvation, repulsive, hydrophobic, electrostatic, activity, and $G$ score.

\section{Results}

The microarray analysis has given an insight on differential expressions of $A L D H$ isoforms in breast cancer tissues. $A L D H 1 A 3$ and $A L D H 18 A 1$ with highest positive mean fold variation and $A L D H 2$ with highest negative mean fold variation were noted as depicted in Table 3 . These results suggest that $A L D H 1 A 3$ and $A L D H 18 A 1$ act as biomarkers for breast cancer. Thus, these may be targeted further for designing inhibitors. ALDH1A3 and ALDH18A1 with 2.22 and 1.93 fold increases respectively were observed. In contrast, $A L D H 2$ with -4.19 fold decrease in expression made us curious to study the DNA sequence of $A L D H 2$.

Table 4 Single-nucleotide polymorphism (SNP) with codon mutation from T to G in ALDH2 gene in breast cancer samples

\begin{tabular}{|c|c|c|c|c|c|c|c|c|}
\hline Chromosome & $\begin{array}{l}\text { Chromosome } \\
\text { position }\end{array}$ & Gene ID & $\begin{array}{l}\text { Gene } \\
\text { name }\end{array}$ & $\begin{array}{l}\text { Biotype } \\
\text { protein } \\
\text { coding (PC) }\end{array}$ & Trancript ID & $\begin{array}{l}\text { Variation } \\
\text { base sample B }\end{array}$ & $\begin{array}{l}\text { SNP quality } \\
\text { sample B }\end{array}$ & $\begin{array}{l}\text { Old codon/new } \\
\text { codon sample B }\end{array}$ \\
\hline chr12 & $1.12 E+08$ & ENSG00000111275 & $\mathrm{ALDH} 2$ & $P C$ & ENST00000552234 & G & 30 & gcT/gcG \\
\hline chr12 & $1.12 E+08$ & ENSG00000111275 & $\mathrm{ALDH} 2$ & $P C$ & ENST00000548536 & G & 30 & gcT/gcG \\
\hline chr12 & $1.12 E+08$ & ENSG00000111275 & $\mathrm{ALDH} 2$ & $P C$ & ENST00000549106 & G & 30 & - \\
\hline chr12 & $1.12 E+08$ & ENSG00000111275 & $\mathrm{ALDH} 2$ & $P C$ & ENST00000416293 & G & 30 & gcT/gcG \\
\hline chr12 & $1.12 E+08$ & ENSG00000111275 & $\mathrm{ALDH} 2$ & $P C$ & ENST00000553044 & G & 30 & - \\
\hline chr12 & $1.12 E+08$ & ENSG00000111275 & $\mathrm{ALDH} 2$ & $P C$ & ENST00000546840 & G & 30 & gcT/gcG \\
\hline chr12 & $1.12 E+08$ & ENSG00000111275 & $\mathrm{ALDH} 2$ & PC & ENST00000261733 & G & 30 & gcT/gcG \\
\hline chr12 & $1.12 E+08$ & ENSG00000111275 & $\mathrm{ALDH} 2$ & PC & ENST00000551906 & G & 30 & Tgg/Ggg \\
\hline
\end{tabular}




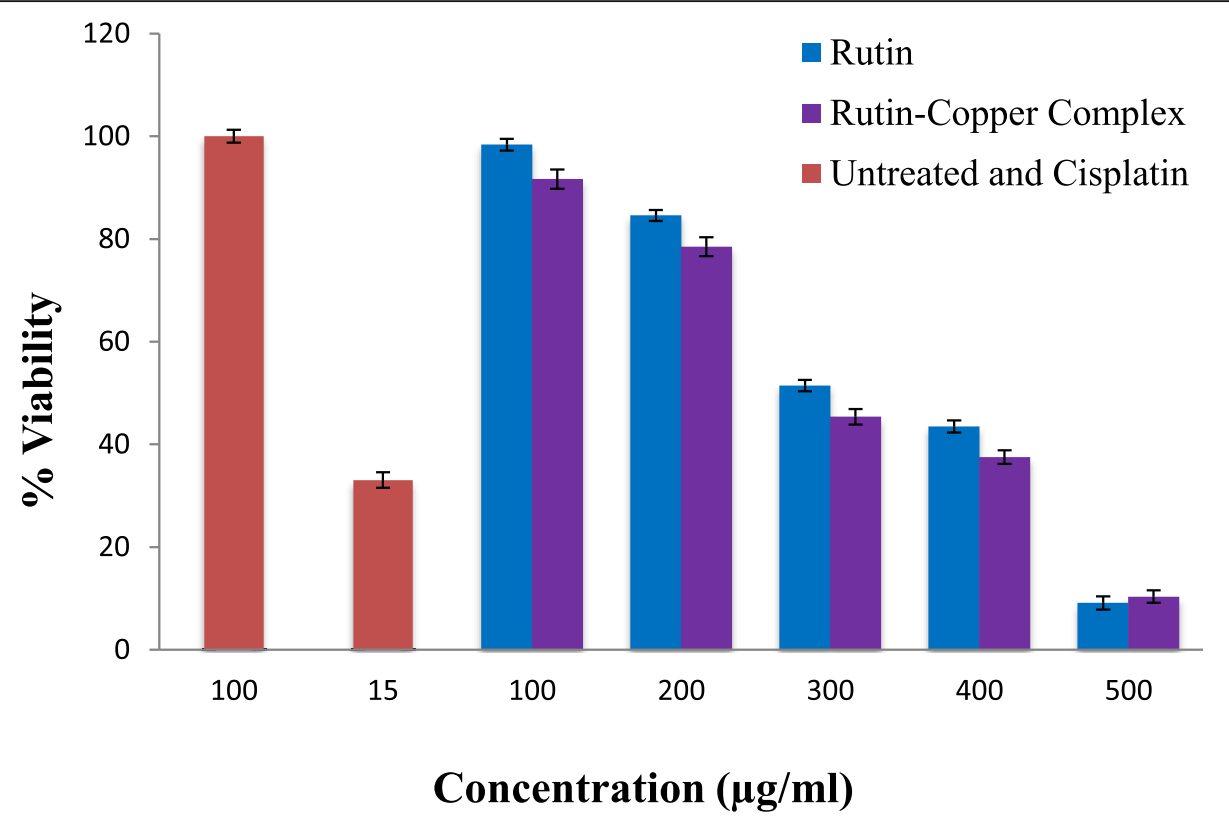

Fig. 2 Effect of rutin and rutin-copper complex on MDA MB-468 cells

\section{Next-generation sequencing (NGS)}

To date, hardly any studies examined the role of $A L D H 2 * 2$ in the development of breast cancer and none of them found any association between $A L D H^{*} 2$ in correlation with the risk of breast cancer [20]. These studies have shown $G$ to $A$ point mutation in $A L D H 2 * 2$. However, in our study, a different novel SNP ' $\mathrm{T}$ to $\mathrm{G}$ point mutation' was observed in breast cancer samples and is depicted in Table 4.

Effect of rutin and rutin-copper complex on cell viability was analyzed through in vitro studies. The analysis was carried out on MDA-MB-468 cells using cell viability assay 3-(4,5-Dimethylthiazol-2-yl]-2,5 diphenyl tetrazolium bromide (MTT assay) for different time periods. The $\mathrm{IC}_{50}$ value of rutin was $144.50 \mu \mathrm{g} / \mathrm{ml}$ and the rutincopper complex was $119.40 \mu \mathrm{g} / \mathrm{ml}$ in MDA-MB-468 cells, with a difference of $25.10 \mu \mathrm{g} / \mathrm{ml}$ (Fig. 2). The lesser $\mathrm{IC}_{50}$ value of the rutin-copper complex may suggest a suitable replacement of the rutin to act as an adjuvant.

Molecular docking studies have revealed that rutin had a best binding affinity with both $A L D H 1 A 3$ and ALDH18A1 among different natural bioactive compounds as shown in Figs. 3 and 4. Schrödinger maestro docking scores of ligands against $A L D H 1 A 3$ and ALDH18A1 are given in (Tables 5 and 6), respectively.

\section{Discussion}

Aldehyde dehydrogenases have a variety of biological effects. It has specifically been linked to different types of cancer, Parkinson's disease, cataract, obesity, etc. $A L D H 1 A 1$ is highly expressed in tissues but not true in case of breast cancer. $A L D H 1 A 3$ is a marker for breast cancer patients [21]. In the present study, $A L D H 1 A 3$ gene was highly expressed compared to normal as reported earlier [22] but $A L D H 18 A 1$ also exhibited high expression in breast cancer. This ultimately proves that $A L D H 18 A 1$ also acts as a biomarker along with $A L D H 1 A 3$. Hence, identifying inhibitors against these may help in better management of breast cancer.

Currently, chemotherapy is widely used to treat a variety of cancers which has its limitations with high toxic side effects to the patients [23]. Hence, research on an alternative approach to treat cancer without side effects is in high demand. Few natural products like flavonoids and polyphenols have better anticancer activity [24]. In silico molecular docking study revealed that rutin has higher binding affinity to both over-expressed $A L D H 1 A 3$ and $A L D H 18 A 1$ gene among 12 selected natural compounds.

As previously reported, the synergistic action of rutin (glycoside) with other chemo drugs, manifests its potential role as an adjuvant for the treatment of breast cancer patients. Recent study reports on flavonoids complexing with macromolecules to enhance their bio-availability and chemo-preventive efficacy. Rutin ( $\mathrm{Ru}$ )-fucoidan $(\mathrm{Fu})$ complex was used to overcome the limitations of bio-availability of rutin molecule [25]. Hence, in our current study, a rutincopper complex was synthesized to study the effects 

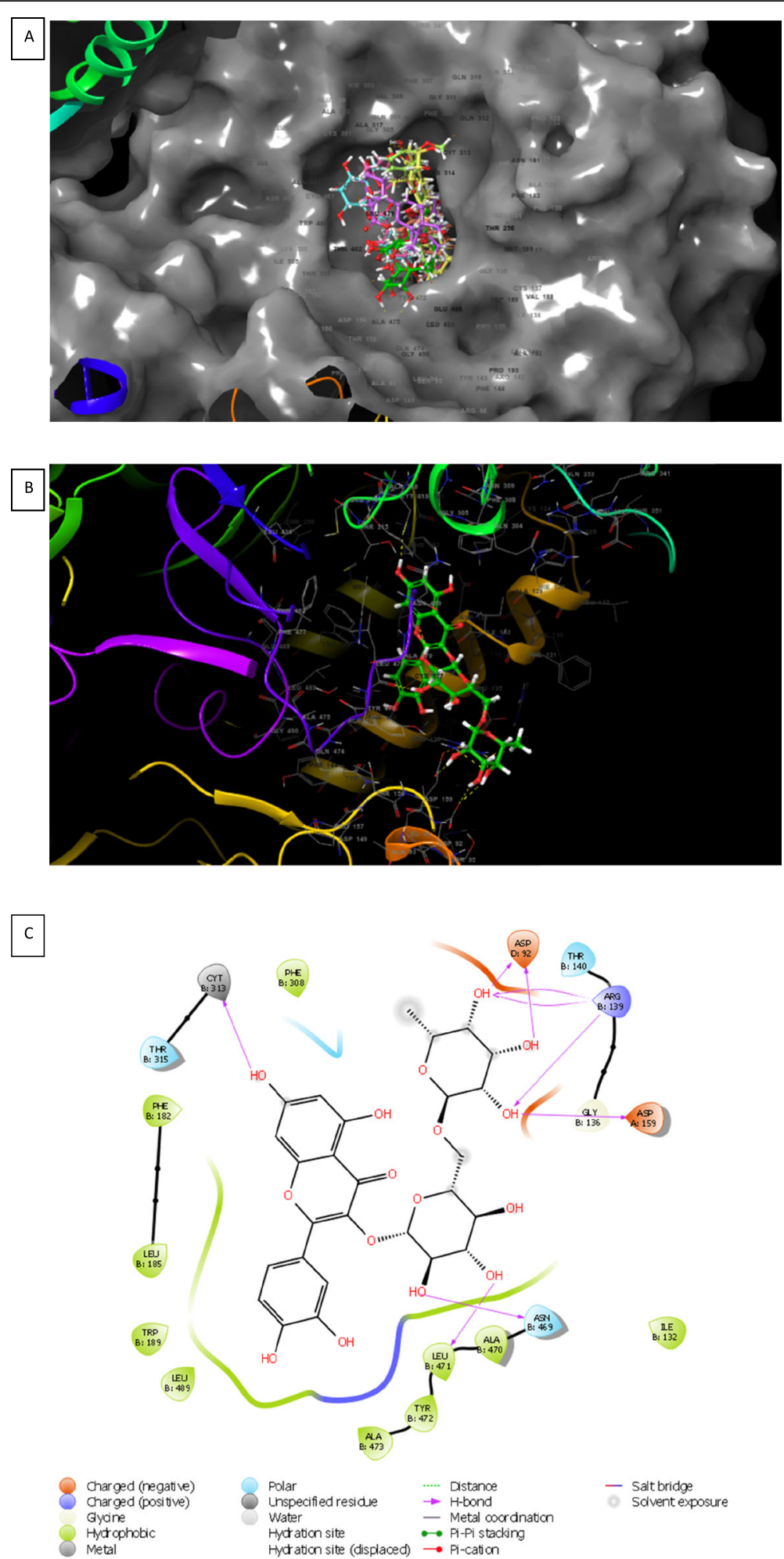

Fig. 3 a The probable binding mode of all ligands to ALDH1A3. $\mathbf{b}$ Interaction diagram of rutin ligand with ALDH1A3 protein: the yellow dotted lines in $3 \mathrm{D}$ figure indicates the hydrogen bond between the ligand and protein receptor. $\mathbf{c}$ Two dimensional interaction diagram indicates the rutin interaction with ALDH1A3, one hydrogen bond is between the ligand and amino acid 471 leucine, 469 aspargine, 92 aspartic acid, 159 aspartic acid, and 139 arginine residue in receptor of protein 

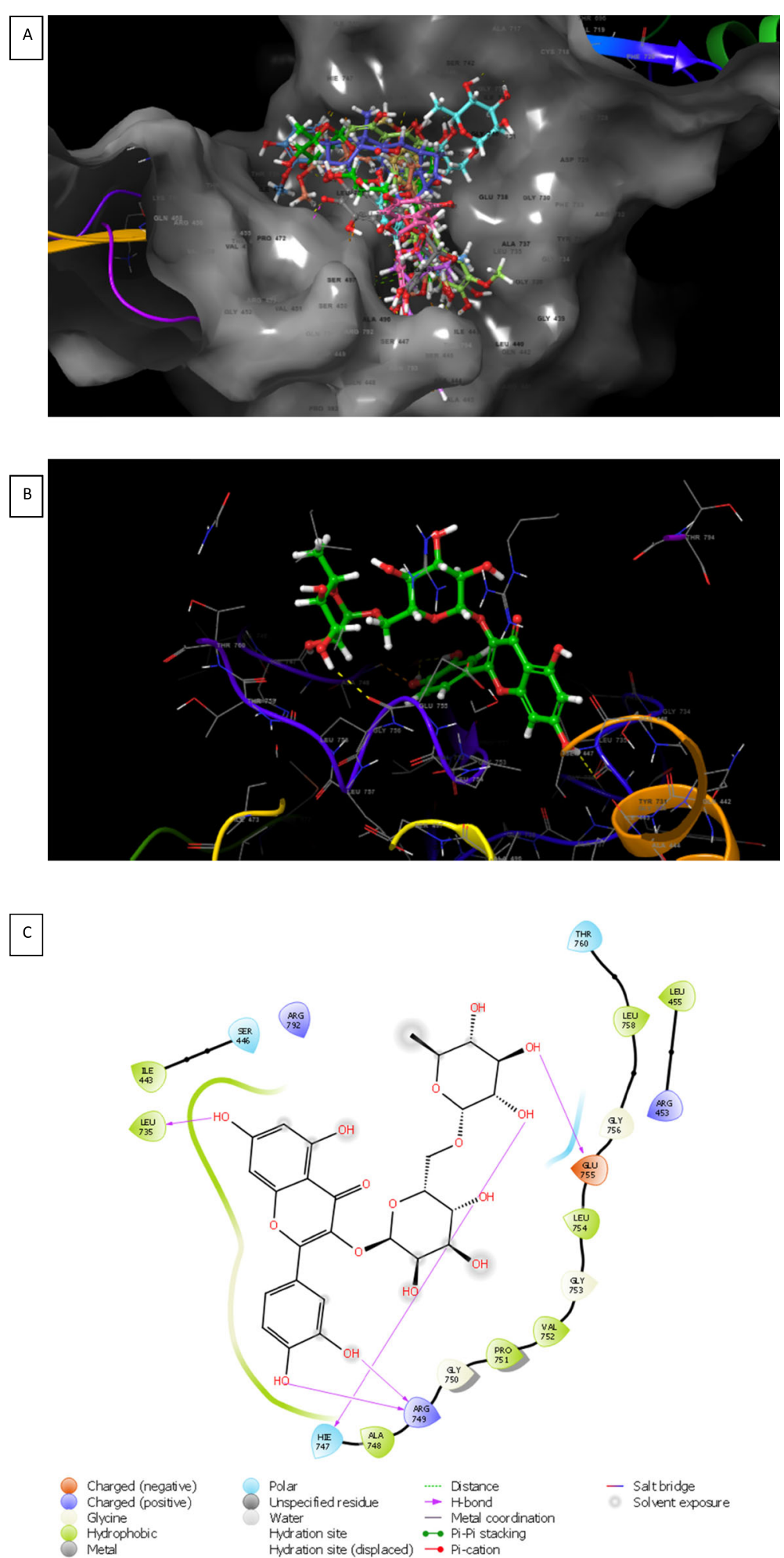

Fig. 4 a The probable binding mode of all ligands to ALDH18A1. b Interaction diagram of rutin ligand with ALDH18A1 protein: the yellow dotted lines in 3D figure indicates the hydrogen bond between the ligand and protein receptor. c Two-dimensional interaction diagram indicates the rutin interaction with ALDH18A1, one hydrogen bond is between the ligand and amino acid 735 leucine, two hydrogen bond with 749 aspargine, 755 glutamic acid, and 747 histidine residue in receptor of protein 
Table 5 Schrödinger maestro docking scores of ligands against ALDH1A3

\begin{tabular}{|c|c|c|c|c|c|c|c|}
\hline Ligand & G score & Dock score & Lipophilic EvdW & PhobEn & Hydrogen bond & Electro & Site map \\
\hline Rutin & -13.68 & -13.67 & -4.28 & -0.4 & -7.17 & -1.93 & -0.05 \\
\hline Epigallocatechin & -10.41 & -10.35 & -3.96 & -0.2 & -5.32 & -1.07 & -0.32 \\
\hline Silibinin & -8.94 & -8.94 & -4.49 & -0.19 & -3.53 & -0.84 & -0.17 \\
\hline Genistein & -8.28 & -8.26 & -4.14 & -0.8 & -2.23 & -0.72 & 0 \\
\hline 24epibrassinolide & -7.79 & -7.79 & -2.76 & -0.68 & -3.81 & -0.89 & 0 \\
\hline 28homocastasterone & -7.74 & -7.74 & -5 & -0.44 & -2.21 & -0.21 & -0.14 \\
\hline Arctigenin & -7.51 & -7.51 & -5.02 & -1.59 & -0.7 & -0.23 & 0 \\
\hline 33'diindolylmethane & -7.44 & -7.44 & -4.97 & -1.11 & -0.7 & -0.4 & 0 \\
\hline Resvertrol & -7.2 & -7.2 & -3.51 & -0.96 & -1.61 & -0.89 & 0 \\
\hline Camptothecin & -7.13 & -7.13 & -5.05 & -0.54 & -0.96 & -0.2 & -0.12 \\
\hline Thymoquinone & -5.1 & -5.1 & -2.56 & -0.64 & -0.7 & -0.1 & -0.6 \\
\hline Ajoene & -4.09 & -4.09 & -3.4 & -0.98 & -0.7 & -0.27 & -0.38 \\
\hline
\end{tabular}

of both rutin and its complex with copper for their potential bioactivity against breast cancer cells. We noticed that the $\mathrm{IC}_{50}$ value decreased to a large extent for rutin-copper complex compared to rutin. Hence, it suggests that the rutin-copper complex is a lead molecule for further studies in replacing rutin to act as an adjuvant in treating breast cancer patients. Further in silico molecular dynamics simulation study and in vivo studies also act as supportive information to understand the nature of rutin-copper complex.

A rare mutation lys/lys genotype of rare SNP rs671, which is associated with increased breast cancer in Asian women, has been recently reported [26]. However, in this study, the expression of $A L D H 2$ was very low in breast cancer tissue samples compared to normal breast tissues. Further, it showed different novel SNP with $\mathrm{T}$ to $G$ rather than $G$ to $A$.

\section{Conclusion}

Like $A L D H 1 A 3, A L D H 18 A 1$ also acts as a biomarker for breast cancer and a novel $A L D H 2$ single-nucleotide polymorphism may also be a prognostic indicator for breast cancer in south Indian women. The computational study reveals that Rutin has greater binding effect on both ALDH1A3 and ALDH18A1 proteins. The rutin-copper complex has a greater effect on breast cancer cell lines as compared to rutin alone. These results should be further validated with in vivo studies and this study needs further investigation with a large number of patient samples.

Table 6 Schrödinger maestro docking scores of ligands against ALDH18A1

\begin{tabular}{|c|c|c|c|c|c|c|c|}
\hline Ligand & $G$ score & Dock score & Lipophilic EvdW & PhobEn & Hydrgen bond & Electro & Site map \\
\hline Rutin & -11.66 & -11.65 & -3.75 & 0 & -6.38 & -1.58 & -0.11 \\
\hline Epigallocatechin & -8.37 & -8.31 & -3.42 & 0 & -4.34 & -1.04 & 0 \\
\hline Silibinin & -6.6 & -6.6 & -2.49 & 0 & -3.28 & -1.15 & -0.09 \\
\hline Resvertrol & -6.35 & -6.35 & -2.33 & 0 & -2.8 & -1 & 0 \\
\hline 28homocastasterone & -5.73 & -5.73 & -2.18 & 0 & -3.29 & -0.72 & 0 \\
\hline Genistein & -5.13 & -5.11 & -2.41 & 0 & -2.12 & -0.99 & 0 \\
\hline 24epibrassinolide & -4.97 & -4.97 & -1.61 & 0 & -2.82 & -1.68 & 0 \\
\hline Arctigenin & -4.64 & -4.64 & -2.79 & 0 & -1.62 & -0.53 & 0 \\
\hline 33'diindolylmethane & -2.66 & -2.66 & -2.8 & 0 & -0.7 & -0.15 & 0 \\
\hline Camptothecin & -2.35 & -2.35 & -2.11 & 0 & -0.83 & -0.29 & -0.24 \\
\hline Ajoene & -2.03 & -2.03 & -2.57 & 0 & -0.62 & -0.31 & -0.18 \\
\hline Thymoquinone & -1.39 & -1.39 & -1.2 & 0 & -0.35 & -0.21 & -0.09 \\
\hline
\end{tabular}




\section{Abbreviations}

ALDH: Aldehyde dehydrogenases; SNP: Single-nucleotide polymorphisms; ER: Estrogen; HER2: Human epidermal growth factor receptor; PR: Progesterone receptor; CSC: Cancer stem cell; CYC: Cyclophosphamide; MTX: Methotrexate; NGS: Next-generation sequencing; FBS: Fetal bovine serum; PDB: Protein data bank; RMSD: Root mean square division; BC: Breast cancer; DMEM: Dulbecco's modified Eagle's medium; BWA: Burrows-wheeler aligner; TNBC: Triple-negative breast cancer

\section{Acknowledgements}

Research team greatly acknowledges the Department of Science and Technology, India.

\section{Authors' contributions}

CMK and PBG designed the research work. SVP, SK, and MRM partake in microarray studies. SVP and MRM partake in in vitro and in silico studies. PHG partake in rutin-copper complex synthesis. BRL and NKP partake in NGS studies. BRL and CMK partake in review and editing. SIM gives directives and technical advices. Finally, all authors have read and approved the research manuscript for publication.

\section{Funding}

The work was supported by Department of Science and Technology, India. DST-PURSE phase II program (Grant No. SR/PURSE PHASE-2/13(G)), which was allotted as central group project to Karnatak University Dharwad, to carry out research work.

\section{Availability of data and materials}

Authors SVP and CMK had full access to all the data in the study. Data will be shared to interesting researchers on request.

\section{Ethics approval and consent to participate}

Karnataka Institute for DNA Research (KIDNAR) is the ethical committee which provided us ethics clearance certificate. Ethical approval number: KIDN AR/2015/11/14, B [8]

\section{Consent for publication}

Not applicable

\section{Competing interests}

There is no conflict of interests regarding the publication of this article.

\section{Author details}

'Department of Studies in Biochemistry, Karnatak University, Dharwad 580003, India. ${ }^{2}$ Karnataka Institute for DNA Research (KIDNAR), Dharwad 580 003, India. ${ }^{3}$ Department of Studies in Chemistry, Karnatak University, Dharwad 580 003, India. ${ }^{4}$ Department of Biochemistry, REVA University, Bengaluru, Karnataka 560064, India. ${ }^{5}$ Department of Bioinformatics and Biotechnology, Karnataka State Akkamahadevi Women's University, Vijayapura, Karnataka 586108, India.

\section{Received: 22 September 2020 Accepted: 4 February 2021}

\section{Published online: 23 March 2021}

\section{References}

1. Ferlay J, Shin HR, Bray F, Forman D, Mathers C, Parkin DM (2010) Estimates of worldwide burden of cancer in 2008: GLOBOCAN 2008. Int J Cancer 127(12):2893-2917

2. Kumar N, Bhatnagar S, Velpandian T (2013) Randomized controlled trial in advance stage breast cancer patients for the effectiveness on stress marke and pain through sudarshan kriya and pranayam. Ind J Palliat Care 19:180185

3. Perou CM, Sørlie T, Eisen MB, van de Rijn M, Jeffrey SS, Rees CA, Pollack JR, Ross DT, Johnsen H, Akslen LA, Fluge O, Pergamenschikov A, Williams C, Zhu SX, Lønning PE, Børresen-Dale AL, Brown PO, Botstein D (2000) Molecular portraits of human breast tumours. Nature 406(6797):747-752

4. Shareef M, Ashraf MA, Sarfraz M (2016) Natural cures for breast cancer treatment. Saudi Pharm J 24(3):233-240

5. Cheang MC, Voduc D, Bajdik C (2008) Basal-like breast cancer defined by five biomarkers has superior prognostic value than triple-negative phenotype. Clin Can Res 14:1368-1376
6. Harbeck N, Penault-Llorca F, Cortes J, Gnant M, Houssami N, Poortmans P, Ruddy K, Tsang J, Cardoso F (2019) Breast cancer. Nat Rev Dis Primers 5(1):66

7. Morgan CA, Hurley TD (2015) Development of a high-throughput in vitro assay to identify selective inhibitors for human ALDH1A1. Chem Biol Interact 234:29-37

8. Vasiliou V, Nebert DW (2005) Analysis and update of the human aldehyde dehydrogenase (ALDH) gene family. Hum Genomics 2(2):138

9. Vidovic D, Huynh TT, Konda P, Dean C, Cruickshank BM, Sultan M, Coyle KM, Gujar S, Marcato P (2020) ALDH1A3-regulated long non-coding RNA NRAD1 is a potential novel target for triple-negative breast tumors and cancer stem cells. Cell Death Differ 27(1):363-378

10. Shoeb M (2008) Anticancer agents from medicinal plants. Bangladesh J Pharmacol 1(2):35-41

11. Greenwell M, Rahman PK (2015) Medicinal plants: their use in anticancer treatment. Int J Pharm Sci Res 6:4103-4112

12. Nyamai DW, Arika W, Ogola PE (2016) Medicinally important phytochemicals: an untapped research avenue. J Pharm Phytochem 1:4

13. Jayameena P (2018) Rutin: a potential anticancer drug against human colon cancer (HCT116) cells. Int J Biol Pharm Allied Sci 7(9):1731-1745

14. Iriti M, Kubina R, Cochis A, Sorrentino R, Varoni EM, Kabała-Dzik A, Azzimonti B, Dziedzic A, Rimondini L, Wojtyczka RD (2017) Rutin, a quercetin glycoside, restores chemosensitivity in human breast cancer cells: rutin restores chemosensitivity in breast cancer cells. Phytother Res 31(10):1529-1538

15. Moitessier N, Englebienne P, Lee D (2009) Towards the development of universal, fast and highly accurate docking/scoring methods: a long way to go: docking/scoring methods-a review. Br J Pharm 153(S1):7-26

16. Kulkarni SS (2012) A comparative study of CDNA microarray analysis of familial and sporadic breast cancer in India. J Med Genet Genomics 4(1):6-12

17. Martina MK, Mirela S, Nela M (2011) Electroanalytical characterization of a copper(II)-rutin complex. Int J Electrochem Sci 6:1075-1084

18. Shah T, Joshi K, Mishra S, Otiv S, Kumbar V (2016) Molecular and cellular effects of vitamin B12 forms on human trophoblast cells in presence of excessive folate. Biomed. Pharmacother 84:526-534

19. Kalirajan R, Rafick MHM, Sankar S, Jubie S (2012) Docking studies, synthesis, characterization and evaluation of their antioxidant and cytotoxic activities of some novel isoxazole-substituted 9-anilinoacridine derivatives. Sci World J 2012:1-6

20. Sangrajrang S, Sato $Y$, Sakamoto H, Ohnami S, Khuhaprema T, Yoshida T (2010) Genetic polymorphisms in folate and alcohol metabolism and breast cancer risk: a case-control study in Thai women. Breast Cancer Res Treat 123(3):885-893

21. Qiu Y, Pu T, Li L (2014) The expression of aldehyde dehydrogenase family in breast cancer. J Breast Cancer 17(1):54

22. Marcato P, Dean CA, Liu RZ, Coyle KM, Bydoun M, Wallace M, Clements D, Turner C, Mathenge EG, Gujar SA, Giacomantonio CA, Mackey JR, Godbout R, Lee PWK (2015) Aldehyde dehydrogenase 1A3 influences breast cancer progression via differential retinoic acid signaling. Mol Oncol 9(1):17-31

23. Ochwang'i DO, Kimwele CN, Oduma JA, Gathumbi PK, Mbaria JM, Kiama SG (2014) Medicinal plants used in treatment and management of cancer in Kakamega County, Kenya. J Ethnopharmacol 151(3):1040-1055

24. Selvakumar P, Badgeley A, Murphy P (2020) Flavonoids and other polyphenols act as epigenetic modifiers in breast cancer. Nutrients 12:761

25. Deepika MS, Thangam R, Sheena TS, Sasirekha R, Sivasubramanian S, Babu MD, Jeganathan K, Thirumurugan R (2019) A novel rutin-fucoidan complex based phytotherapy for cervical cancer through achieving enhanced bioavailability and cancer cell apoptosis. Biomed Pharmacother 109:1181-1195

26. Ugai T, Milne RL, Ito H, Aronson KJ, Bolla MK, Chan T, Chan CW, Choi JY, Conroy DM, Dennis J, Dunning AM, Easton DF, Gaborieau V, Gonzalez-Neira A, Hartman M, Healey CS, Iwasaki M, John EM, Kang D, Kim SW, Kwong A, Lophatananon A, Michailidou K, Taib NAM, Muir K, Park SK, Pharoah PDP, Sangrajrang S, Shen CY, Shu XO, Spinelli JJ, Teo SH, Tessier DC, Tseng CC, Tsugane S, Vincent D, Wang Q, Wu AH, Wu PE, Zheng W, Matsuo K (2019) The functional ALDH2 polymorphism is associated with breast cancer risk: a pooled analysis from the breast cancer association consortium. Mol Genet Genomic Med 7(6):707

\section{Publisher's Note}

Springer Nature remains neutral with regard to jurisdictional claims in published maps and institutional affiliations. 